\title{
New optical engineering and instrument design programs at the University of California, Irvine Extension
}

Donn Silberman, Valentina Doushkina

Donn M. Silberman, Valentina V. Doushkina, "New optical engineering and instrument design programs at the University of California, Irvine Extension," Proc. SPIE 7783, Optics Education and Outreach, 77830N (31 August 2010); doi: $10.1117 / 12.860060$

Event: SPIE Optical Engineering + Applications, 2010, San Diego, California, United States 


\title{
New Optical Engineering \& Instrument Design Programs at The University of California, Irvine Extension
}

\author{
${ }^{\mathrm{a}, \mathrm{b}, \mathrm{d}}$ Donn M. Silberman, ${ }^{\mathrm{a}, \mathrm{c}, \mathrm{d}}$ Valentina V. Doushkina \\ ${ }^{a}$ Optics Institute of Southern California, 31 Blackbird Lane, Aliso Viejo, CA 29656 \\ ${ }^{\mathrm{b}}$ PI (Physik Instrumente) L.P., 5420 Trabuco Rd., Irvine, CA 92620 \\ 'Qioptiq Polymer, Inc., 1318 Palomares Ave. LaVerne, CA 91750 \\ ${ }^{\mathrm{d}}$ University of California, Irvine, Extension, Building 234, Irvine, CA 92697
}

\begin{abstract}
Three years ago we reported on a new optics education program established at the Irvine Center for Applied Competitive Technologies (CACT) at the Advanced Technology and Education Park (ATEP) operated by the South Orange County Community College District (SOCCCD). This paper reports on new Optical Engineering and Instrument Design Programs now being offered through the University of California, Irvine Extension. While there are some similarities between the two programs, the differences are mainly the students' level. The community college level programs were targeted primarily at technicians and junior level engineers. The university level programs are targeted at senior level engineering and physical sciences university students, graduate and post graduate students and designers in industry. This paper reviews the reasons for establishing these certificate programs and their content, the students' motivations for taking them and their employers' incentives for encouraging the students.
\end{abstract}

Keywords: Optics education, lens design, optical system design, optomechanical design, optical instrument design, optical engineering education.

\section{INTRODUCTION}

In 2007, we reported on a new program offered at the Irvine CACT, which since the end of that year has gone through some changes in administration and is currently seeking to reconstitute itself based on the technician training of OPTEC, The National Center for Optics and Photonics Education, an NSF Sponsored program. The new program reported on in this paper has taken the program we previously reported on to the next level where the students are senior level undergraduate, graduate and post graduate students and individuals working in industry. Graduates of these programs will be optical engineers and optical instrument designers. Since the basic details of these courses are built upon those reported on in 2007, this paper will provide an employment outlook, an overview of the new programs, how they are organized and offered and their curriculum.

\section{EMPLOYMENT OUTLOOK}

According to the Bureau of Labor Statistics, the number of technical positions related to the optical products industry will grow 18\% between 2006 and 2016 due to increasing industry demands. Expected areas of growth include:

Optical Instruments that focus on medical, clean energy, entertainment, semiconductor, nanotechnology and big science projects are all areas of growth.

New medical equipment to provide greater precision

Cancer and genetic research and implementation

Solar photovoltaic, nuclear fusion \& fission, laser systems

Photolithography systems for semiconductor manufacturing

Job Prospects: Retiring labor force, New technologies

Optics Education and Outreach, edited by G. Groot Gregory, Proc. of SPIE Vol. 7783,

$77830 \mathrm{~N} \cdot$ ? 2010 SPIE $\cdot$ CCC code: $0277-786 \mathrm{X} / 10 / \$ 18 \cdot$ doi: $10.1117 / 12.860060$ 
Optics based industries in Southern California (and many other geographic areas) include:

Optometry
Astronomy
Microscopy
Photography
Scanning Technologies
Photolithography
Telecommunications
Fundamental Physics / Optics
Lighting
Transportation
Art \& Entertainment

\author{
Medical Lasers \\ Industrial Lasers \\ Optics Design \& Manufacturing \\ Color - printing \\ Optical Metrology \\ Gemology / Mineralogy \\ Holography - Science \& Art \\ Ecology / Environmental Science \\ Atmospheric Sciences \\ Commercial Applications \\ Renewable Energy
}

Companies hiring graduates form these programs will include, for example, Corporate Members of the Optical Society of Southern California and SPIE. Also, there are many other prospective employers in the industries cited above and in government agencies and laboratories.

\section{OPTICAL ENGINEERING \& INSTRUMENT DESIGN PROGRAM OVERVIEW}

The two certificate programs offered, Optical Engineering and Optical Instrument Design, are built upon core courses in lens design, optical system design and optomechanical system design. Then there are other elective courses including fundamental optics (geometric and physical), laser systems, fiber optics systems, optical metrology, precision motion control, 3D mechanical design and vibration control. A graphic representation is shown in the figure below.

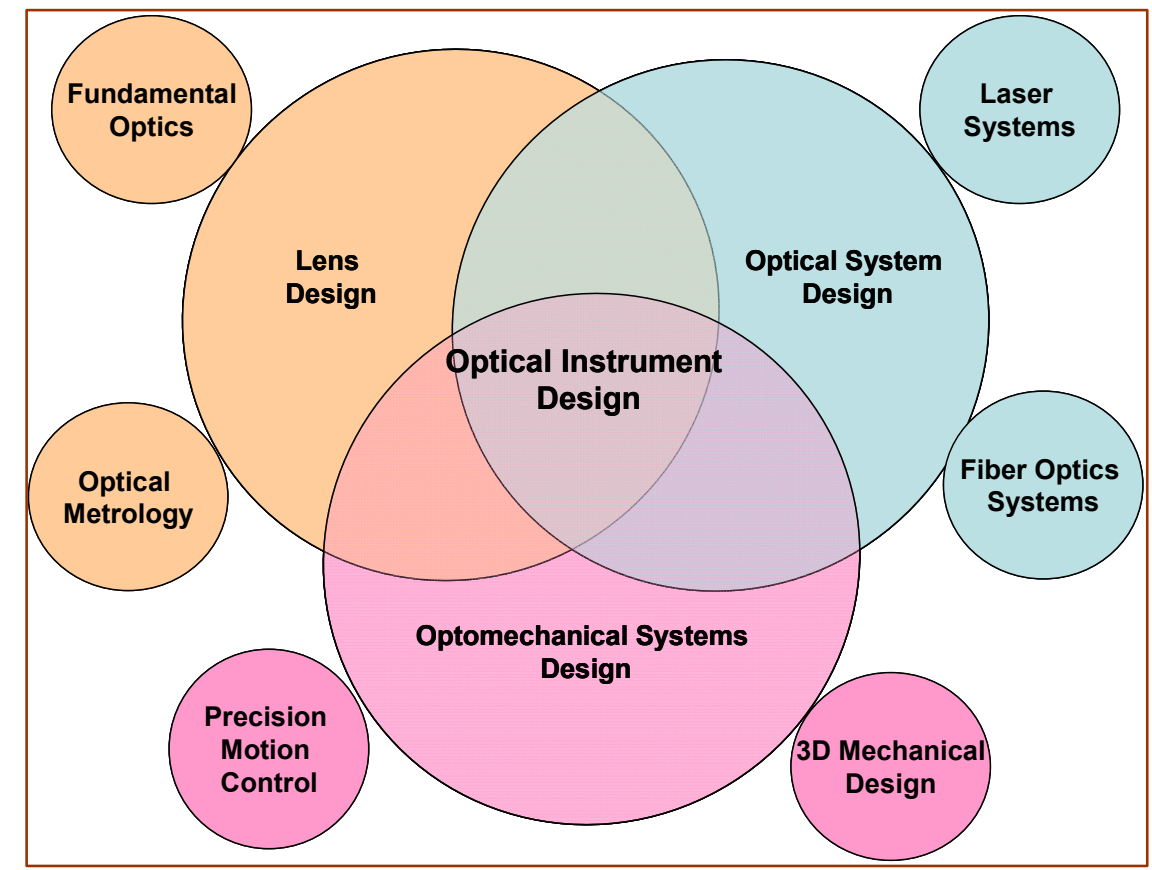

Fig. 1. Modified Venn diagram showing the relationships between courses in the Optical Engineering and Optical Instrument Design Programs. Core courses are in the three large circles and elective courses are in the smaller circles around the periphery. 
The core courses in these programs offer hands-on educational and design experience for students in the optics industry. The lens design courses provide three basic skills: manual, design code, and design philosophy. The optical systems design and analysis courses begin with modeling coordinate breaks, multi-configurations and evolve into systems analysis, tolerancing and athermalization. The optomechanical component design course and then the optical instrument design course integrate the optical and the mechanical systems to perform effectively. These are the main skills employers want to fill the growing needs of local optics companies and companies using optics. The elective courses offered in these programs allow students of different backgrounds to choose topics of interest that may meet their business or education requirements, including fundamental optics courses if they need that before taking the design courses. These elective courses include: Geometric Optics, Physical Optics, Introduction to Lasers, Introduction to Fiber Optics, Optical Metrology \& Interferometry, Precision Positioning \& Motion Control, Vibration Control and 3D Mechanical Design. Also, a Special Projects course will be offered for students wishing to complete their elective course requirements using a project based on their business or educational situation.

\section{TEACHING PHILOSOPHY AND IMPLEMENTATION}

The teaching philosophy of the core courses and programs are to fuse the 'lectures' with the hands-on learning by doing lesson implementation during the class period. The courses in this program last 10 weeks and meet once each week for 3 hours. Originally (and during the $2005-2007$ period), all of the elective courses were designed and had the lectures at most half of the class period and the hands-on labs are at least half the class period. For example, if a class runs three hours per day, then at most 1.5 hours will be lecture and the rest of the time the students will be working with lenses and mirrors and light sources. This model is in the process of changing for some of the elective courses, where the lectures may be offered through On-Line Distance Education model and the Hands-On Labs may be offered as separate courses both live in-class and through some non-traditional distance learning with "Kits".

For the lens, optical system and instrument design program courses, the students each have a computer and design environment (like ZEMAX or CODE V Optical Design software or 3D SolidWorks Mechanical Design software) in which to follow the instructor as she introduces new concepts, terminology and design approaches. The students also learn about navigating around in their new design environments and where many of the key levers are located and how they function. During each class period, the students are given design problems to work on during the class and explore and express their own creativity and design approaches under the guidance of the instructor. By the end of each class period the students have had the hands-on experience that they can use to complete their homework problems and take their new knowledge back to their daytime work place and use.

Beginning in the Fall of 2010, a new Live On-Line Distance Education concept will be implemented where the instructor is teaching live in a classroom of maybe 10 students and maybe another 10 students are Live On-Line via WebEx watching the instructor's every move on the computer screen. The remote students will also have Live Chat and audio capability throughout each class period. This will enable students to participate in these courses Live from any computer with an internet connection. These class sessions will also be recorded and archived for the current term so students can replay lectures for additional confirmation of instruction.

\section{UPDATE FROM 2007 - 2009}

In 2007, we ran the first cohort at the Irvine CACT and the core program structure was based on three (3) courses, each 16 weeks long. They were Lens Design, Optical System Design and Optomechanical \& Instrument Design. Most of the students took all three courses, which ran from January through December, with a week break between each course. By the end of the year, the students had learned quite a lot (less during the last 16 weeks due to technical computer difficulties at the then new CACT @ ATEP facility) but were a bit overwhelmed by the amount of technical material they were asked to master. The one major takeaway for the instructor and program administrators was that more time for each course or set of materials would help the students digest the material and be more successful back at their school or business. 
This first cohort of students, shown with the instructor (and co-author of this paper) in the front and center, include two with Ph.D.s, two Past President of the OSSC (one not shown), one Sr. Technician and three with BS or MS degrees. These students, like the current cohort, formed a working group where they would get together (virtually) between classes and collaborate on homework assignments and prepare for exams. This community of optical students is one goal of this program.

During 2008, the administration of the CACT @ ATEP underwent significant change and this optics program administration sought to transfer this program to UC Irvine Extension. During that process, towards the end of 2008, the UC Irvine Extension Science \& Engineering Program Manager left and the approval process was delayed until the current Program Director, Dave Dimas, was brought on board in the Spring of 2009. The current cohort began the program in the Fall of 2009 and they are

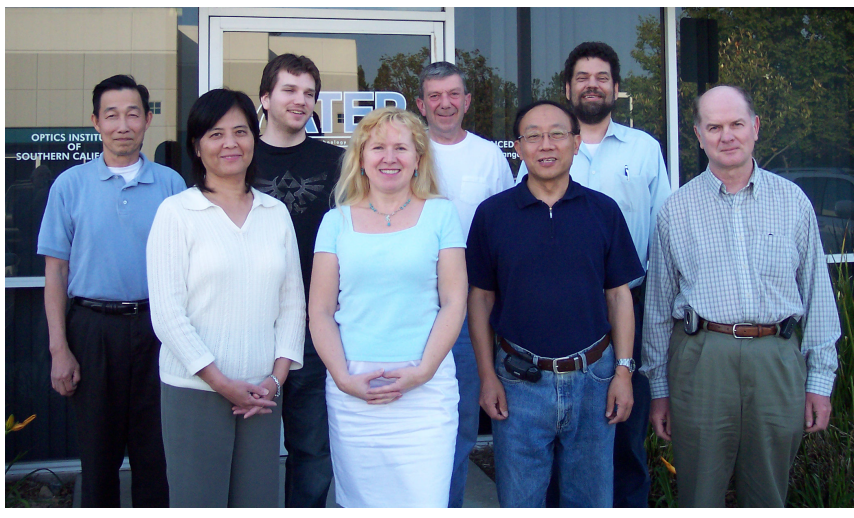

Fig. 2. Photograph (taken in 2007) showing first cohort of students and instructor for the program that was started at the CACT@ ATEP facility known as the Reynolds Building, in Irvine, CA. about to complete their fourth course. The new UC Irvine Extension team has provided excellent support in all respects including administration, marketing, facilities, IT and human resources (instructor processing \& support.) Also, an extensive Advisory Committee of top UC Irvine faculty and industry professionals has been assembled to review and support the programs.

\section{OPTICAL ENGINEERING \& INSTRUMENT DESIGN PROGRAMS}

The current courses offered through UC Irvine Extension Engineering, Sciences and Information Technologies department can lead students to certificates in either Optical Engineering or Optical Instrument Design or both.

The five course Optical Engineering Certificate Program requires 15 credit units (each course is 3 units) with three required courses ( 9 credit units) - Lens and Optical Systems Design Courses and two elective courses (6 credit units) which provide industry-specific subject area concentration within optics, lasers, fiber optics, optical metrology and special projects.

The five course Optical Instrument Design Certificate Program requires 15 credit units (each course is 3 units) based on two required courses (6 credit units) - Optomechanical \& Optical Instrument Design Courses, with three elective courses ( 9 credit units) which provide industry-specific subject area concentration within mechanical design, precision positioning \& motion control, vibration control and special projects. The following tables show required and elective courses offered.

\begin{tabular}{|c|c|}
\hline OPTICAL ENGINEERING REQUIRED COURSES & \multirow[b]{2}{*}{ Units } \\
\hline ( 9 credit units) & \\
\hline Advanced Lens Design & 3 \\
\hline Introduction to Optical Systems Design & 3 \\
\hline Advanced Optical Systems Design & 3 \\
\hline $\begin{array}{l}\text { OPTICAL INSTRUMENT DESIGN REQUIRED COURSES } \\
\text { (6 credit units) }\end{array}$ & Units \\
\hline Optomechanical Component Design & 3 \\
\hline Optical Instrument Design & 3 \\
\hline
\end{tabular}




\begin{tabular}{|l|c|}
\hline \multicolumn{1}{|c|}{ ELECTIVE COURSES } & Units \\
\hline Geometric Optics & 3 \\
\hline Physical Optics & 3 \\
\hline Introduction to Lens Design (pre-requisite to Adv. Lens Design) & 3 \\
\hline Introduction to Laser & 3 \\
\hline Introduction to Fiber Optics & 3 \\
\hline Optical Interferometry \& Metrology & 3 \\
\hline Introduction to Solid Works & 3 \\
\hline Precision Positioning \& Motion Control for Optical Systems & 3 \\
\hline Introduction to Vibration Control & 3 \\
\hline Special Projects & 3 \\
\hline
\end{tabular}

Note: Classes are subject to change. For the most current schedule of classes, please go online to the UCI Extension catalog at www.unex.uci.edu.

Fig. 3. Optical Engineering and Optical Instrument Design Programs required and elective courses.

Since 2005, when the OISC and Irvine CACT partnered to provide Hands-On Optics courses through Irvine Valley College and then ATEP, an on-going relationship has been nurtured through administrative transitions at the community college. Earlier this year, a collaborative agreement was reached between ATEP and UC Irvine Extension, to allow some UC Irvine Extension (elective) hands-on lab courses in these programs to be taught at the ATEP facility, as was done back in 2007. Examples of these include the Geometric Optics and Optical Interferometry \& Metrology courses shown below.
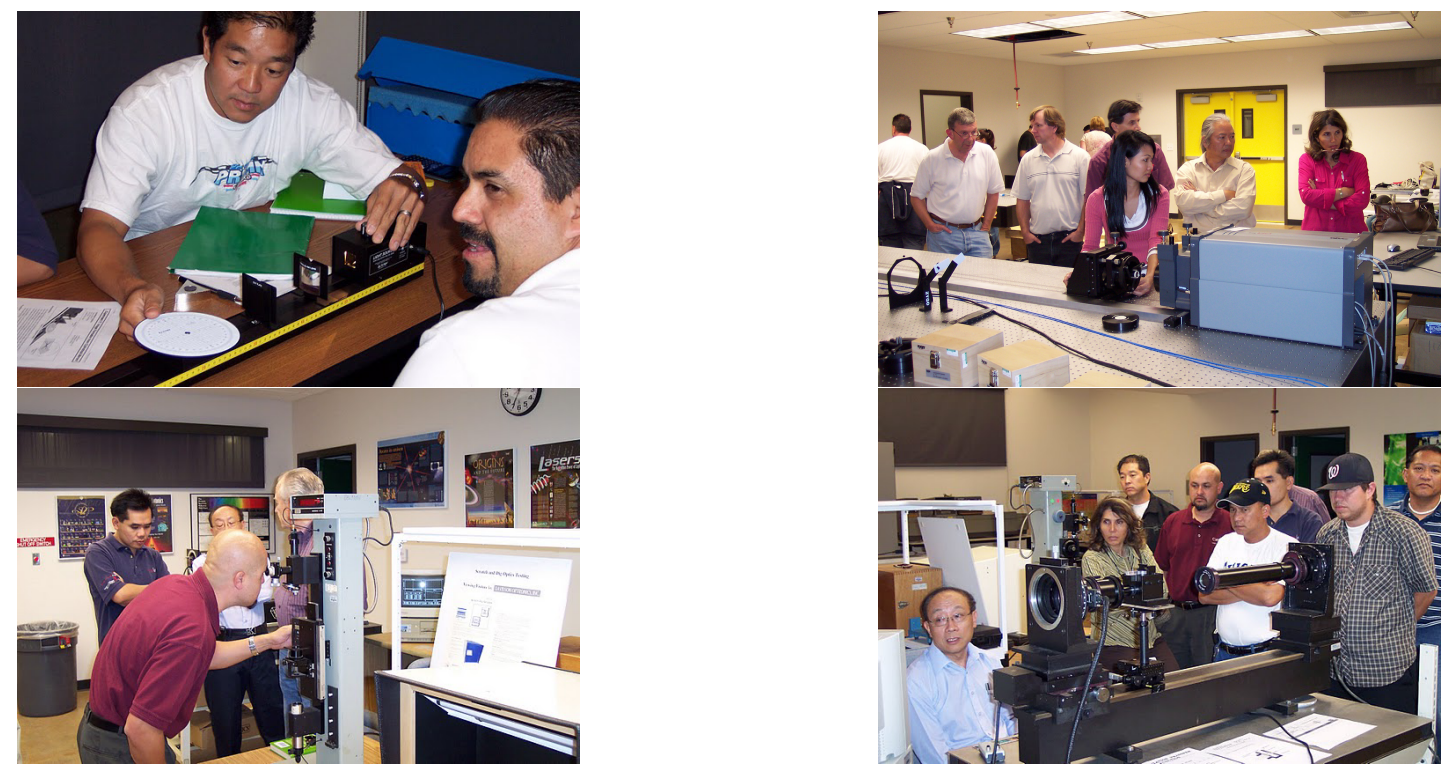

Fig. 4. Photographs showing students and instructors in the Hands-On Labs classes at CACT@ATEP. Clockwise from the top left. a) Geometric Optics students usng the Pasco 8500 Optics Bench, b) Optical Metrology \& Interferometry students using a Zygo interferometer, c) Students using an Optical Measurement Bench with a USAF 1951 Resolution Target, d) Instructor demonstrating an Ealing MTF OpticalMeasurement Bench. 
As the ATEP facility continues to grow into its new spaces, a long term perspective is taken for both the UC Irvine Extension Optical Engineering \& Instrument Design programs and ATEP Optics and Photonics Technician Training Programs. These two programs are seen as building the Southern California optical community's workforce of the future, which has already begun. The Informal Optics Educational Outreach Programs discussed in a separate paper at this conference seek to build a pipeline of K-12 students that will find interest in the optics and related industries as career choices.

\section{CONCLUSIONS}

While lens design, optical systems design and optomechanical systems design has been taught for many years at many distinguished educational institutions, we believe that these new Optical Engineering \& Optical Instrument Design programs are unique for many reasons. They provides hands-on educational and design experience for students in the optics industry; and for students with different technical backgrounds, we offer additional assistance. As an example, for students wishing to enter the optics industry at the engineering level, but do not have the general optics background, the program offers fundamental optics courses that can be taken prior to the Lens Design courses. The new Live On-Line format will offer students all over the world the opportunity to take advantage of the unique teaching philosophy and implementation offered by these courses.

The on-going relationship with the ATEP facility offers UC Irvine students the opportunity to experience hands-on optics instruments to supplement their lens and optical instrument design course work. These courses have been developed and implemented to fill the growing needs of local optics companies and companies using optics. Students, scientists and engineers completing these courses can help produce better optical instruments in shorter time cycles and reduced costs.

From these programs the students learn that effectively engineered optical instruments are the result of the successful integration of optical and mechanical designs derived and analyzed from the given specifications.

\section{ACKNOWLEDGEMENTS}

The Optics Institute of Southern California and the Optical Society of Southern California has supported these programs with the time and efforts of many volunteers.

The authors may be contacted at the Optics Institute of Southern California http://oisc.net or at the Optical Society of Southern California www.ossc.org 